\title{
Criminologia e Psicanálise: uma leitura dos atos infracionais na adolescência
}

\section{Criminology and Psychoanalysis: an interpretation of acts of infraction during adolescence}

\section{Criminología y Psicoanálisis: una lectura de los actos infraccionales en la adolescencia}

\author{
Juliana Marcondes Pedrosa de Souza* \\ Universidade Federal de São João del Rei - UFSJ, Belo Horizonte, Minas Gerais, \\ Brasil
}

\section{Roberto Calazans**}

Universidade Federal de São João del Rei - UFSJ, Belo Horizonte, Minas Gerais, Brasil

\section{J acqueline de Oliveira Moreira***}

Pontifícia Universidade Católica de Minas Gerais - PUC-Minas, Belo Horizonte, Minas Gerais, Brasil

\begin{abstract}
RESUMO
Quando nos referimos ao ato infracional, destacamos uma questão que diz respeito ao olhar da Psicanálise para as possíveis motivações inconscientes que esse ato pode vir a desvelar, em contraposição ao olhar do Direito, que visa à punição em prol do cumprimento das normas. Em ambos os posicionamentos, têm-se as implicações desse ato no social, não sendo possível abrir mão do enquadre proposto pelas diretrizes legais a todos os que cumprem uma medida socioeducativa. Contudo, há que se reconhecer o estatuto subjetivo implícito no ato infracional, que o faz único em cada história de vida. Nesse contexto, é importante levar o ato infracional à prática do dizer no cumprimento da medida socioeducativa. Este artigo buscará articular as contribuições das teorias psicanalíticas (especificamente freudo-lacanianas e millerianas) sobre os atos do adolescente infrator, através da escuta, buscamos compreender a importância desse dispositivo quando se consegue levar 0 adolescente a se questionar sobre 0 ato infracional que tem implicações em sua própria história de vida.
\end{abstract}

Palavras-chave: criminologia, ato infracional, adolescência.

\section{ABSTRACT}

When acts of infraction are discussed, an important issue which should be highlighted concerns the Psychoanalysis' view on possible unconscious reasons that may be revealed by these sorts of acts in contrast with the view from the Law, which targets punishment in order to ensure the observance of society's rules. In both points of view, social implications of 
these acts are taken into consideration, thus it is not possible to let go of the framing proposed by legal directives to those who serve social-educational measures. Nonetheless, one should consider the implicit subjectivity of acts of infraction, which makes each act unique in each life story. In this context, it is important to connect the act of infraction to the practice of speech during the serving of the measure. This article aims to articulate the contributions of psychoanalytic theories (more specifically, the contributions given by Freud, Lacan and Miller) on criminology and on acts with the listening of the transgressor adolescent, as well as to comprehend the importance we give to the moment in which the adolescents start questioning themselves on their acts of infraction and their implications on their own lives.

Keywords: criminology, acts of infraction, adolescence.

\begin{abstract}
RESUMEN
Cuando nos referimos al acto infracciónale, una cuestión a ser destacada se relaciona con la mirada del Psicoanálisis hacia las posibles motivaciones inconscientes que ese acto puede venir a desvelar, en contraposición a la mirada del Derecho, que mira a la punición en pro del cumplimiento de las normas. En ambos los posicionamientos, se tienen las implicaciones de ese acto en lo social, no siendo posible abrir mano del encuadre propuesto por las directrices legales a todos los que cumplen una medida socioeducativa. Sin embargo, hay que reconocer el estatuto subjetivo implícito en el acto infracciónale, que lo hace único en cada historia de vida. En ese contexto, es importante llevar el acto infracciónale a la práctica del hablar en el cumplimiento de la medida socioeducativa. Este artículo buscará articular las contribuciones de las teorías psicoanalíticas (específicamente freudolacanianas y millerianas) sobre la criminología y sobre los actos con la escucha del adolescente infractor, y comprender la importancia que atribuimos al momento en que se logra llevar esos adolescentes a cuestionarse sobre el acto infracciónale que tiene implicaciones en su propia historia de vida.
\end{abstract}

Palabras clave: criminología, acto infracciónale, adolescencia.

\title{
I ntrodução
}

O Estatuto da Criança e do Adolescente (ECA), promulgado em 1990 pela Lei 8.069 , pode ser pensado como legislação brasileira de vanguarda para tratar os direitos e garantias dos brasileiros na faixa etária que vai de 0 a 18 anos. Seguindo a proposta de Saraiva (2009), podemos localizar três sistemas no Estatuto: o primeiro refere-se às Políticas Públicas de Atendimento a crianças e adolescentes; a exposição das Medidas Protetivas constitui o segundo sistema; e, por fim, temos o sistema composto pelas Medidas Socioeducativas, que são descritas pelo artigo 112. Segundo Moreira, Romagnoli, Melgaço, Dias e Bouzada (2014),

a proposta do Estatuto da Criança e do Adolescente, regida pela Doutrina da Proteção Integral, é inovadora e essencial para a mudança no curso da história brasileira no que concerne 
aos direitos das crianças e dos adolescentes e ao tratamento dado aos adolescentes envolvidos com a criminalidade (Moreira et al., 2014, p. 75).

Entretanto, as citadas autoras mencionam também os perigos no interior do Sistema das Medidas Socioeducativas da disciplinarização dos corpos, que em termos foucaultianos se refere ao apagamento da singularidade e à construção da estigmatização do adolescente como um infrator (Moreira et al., 2014). Assim, se, por um lado, o ECA representa um avanço, por outro, é preciso ficar atento aos perigos de se reduzir a vida destes sujeitos a um objeto totalmente manobrável pelo Estado, algo a que Lacan (1948/1998a), em seu texto A agressividade em Psicanálise, já chamava de risco de desumanização daquele que comete atos ilícitos.

Essa desumanização apontada por Lacan tem como ponto de partida a retirada de responsabilização do sujeito quanto ao seu ato. Por essa razão, a este artigo interessa um aspecto importante dessa questão: refletir sobre as implicações de se definir uma ação criminosa do adolescente como ato infracional.

Segundo o Artigo 103 do ECA, "considera-se ato infracional a conduta descrita como crime ou contravenção penal". Já a diferença entre os atos condenáveis cometidos por crianças com menos de 12 anos, por adolescentes com idades entre 12 e 18 anos e por maiores de 18 anos é explicada por Aquino (2012): no caso do "ato infracional cometido por criança (até 12 anos), aplicam-se as medidas de proteção" (Aquino, 2012, s.p.); os adolescentes (idades entre 12 e 18 anos) respondem por meio de medida socioeducativa; e, se o infrator tiver mais que 18 anos, os termos adotados são "crime", "delito" ou "contravenção penal". É importante salientar que, no caso de pessoas com idade superior a 18 anos, não cabe o termo "ato infracional", e sim "crime".

O ato infracional, segundo Aquino, é um "ato condenável, de desrespeito às leis, à ordem pública, aos direitos dos cidadãos ou ao patrimônio, cometido por crianças ou adolescentes" (Aquino, 2012, s.p.). Ainda que o artigo 103 do ECA faça uso do termo "ato infracional", para uma definição mais clara também lança mão da palavra "crime". Acreditamos que o ponto que determina o uso da expressão "ato infracional" seja a questão da inimputabilidade atribuída aos adolescentes por apresentarem, segundo o art. 26 do Código Penal brasileiro, desenvolvimento mental incompleto. Segundo Aquino, no caso do art. 103, embora a prática do ato seja descrita como criminosa, o fato de não existir a culpa em razão da imputabilidade penal, a qual somente se inicia a partir dos 18 anos, utiliza-se a expressão "ato infracional".

No entanto, como afirmam Silvia Elena Tendlarz e Carlos Garcia (2013), essa noção de inimputabilidade se ampara em quatro 
condições que, aos olhos da psicanálise, colocam uma questão que permite diferenciar dois níveis de responsabilidade: a jurídica e a subjetiva:

Liberdade, consciência, compreensão e razão são quatro condições que, desde a psicanálise, pertencem à órbita do ego, às funções do ego e não do sujeito, daí que culpa e responsabilidade devem ser conceituados em outros termos. Isso não significa que não devam ser levados em conta, mas que na avaliação da passagem ao ato homicida são avaliadas de formas diferentes (Tendlarz \& Garcia, 2013, p. 39)

A questão do ato infracional introduz assim uma importante pergunta para a psicanálise: quem responde por seus atos? Pois se por um lado a questão da imputabilidade está ligada à dimensão de um sujeito jurídico que pressupõe, de acordo com Tendlarz e Garcia (2013), a dimensão consciencial do eu em suas escolhas, sabemos que existe uma outra dimensão que aponta para o sujeito do inconsciente e o sentimento de culpa, tornando a questão mais sensível principalmente quando estamos às voltas com os efeitos subjetivos de uma pena ou medida de segurança. Desse modo, a inimputabilidade introduz uma dimensão que podemos chamar de nebulosa: os efeitos subjetivos não se restringem a avaliar a questão em termos consciência ou não do ato, podendo a possibilidade da assunção subjetiva do que foi feito servir de esteio para que novos atos dessa natureza não sejam mais cometidos, o que ultrapassa o regime do direito. Este é o problema que motiva as questões deste artigo, principalmente no que tange ao que a psicanálise pode nos oferecer para a compreensão dos termos "crime" e "ato infracional".

Ao refletirmos, portanto, sobre a clínica do ato infracional estamos obrigatoriamente no campo da adolescência. Lacadée (2011) situa a adolescência como a mais delicada das transições na medida em que, confrontado pelas questões da sexualidade e pelos demais impasses da vida, o adolescente, diante do real, precisa inventar sua própria resposta à pergunta "quem sou eu?", lançando mão dos recursos que tem disponíveis. Para alguns adolescentes a saída possível se dá pela via do ato infracional, prevalecendo o fazer no lugar do dizer. Pensamos que alguns adolescentes que se envolvem na criminalidade podem encenar em atos infracionais essa tentativa de saída do malestar "que não pode ou não soube encontrar no discurso ambiente uma forma de ser refreado, pontos de ancoragem nos quais fixar seus transbordamentos ou maneiras melhores de saber fazer com isso" (Lacadée, 2011, p. 8).

A partir dessas colocações, a questão que norteia o artigo é: como articular a escuta do adolescente infrator com as contribuições da 
teoria psicanalítica (especificamente freudo-lacanianas e millerianas) sobre a criminologia e sobre os atos?

\section{Psicanálise e crime: mito fundante}

A teoria freudiana trabalha o tema do crime a partir da culpa como algo estrutural da constituição do sujeito em sua relação com o Outro. Na obra freudiana não encontramos o estudo de um caso factível de um crime, sendo o tema apresentado através do mito e da literatura. E é exatamente por não se debruçar sobre um acontecimento factual que Freud (1913/1980b) pensa o crime como condição para a cultura. O parricídio é apresentado nos mitos do Édipo e do assassinato do pai em Totem e tabu e, ainda, no estudo da obra de Dostoievski, Os irmãos Karamazov.

Em Totem e tabu (1913/1980b), Freud apresenta a tese da origem da civilização a partir do assassinato do pai. No texto Psicologia de grupo e análise do ego encontramos uma síntese desta tese:

Em 1912 concordei com uma conjectura de Darwin, segundo a qual a forma primitiva da sociedade humana era uma horda governada despoticamente por um macho poderoso. Tentei demonstrar que os destinos dessa horda deixaram traços indestrutíveis na história da descendência humana e, especialmente, que o desenvolvimento do totemismo, que abrange em si os primórdios da religião, da moralidade e da organização social, está ligado ao assassinato do chefe pela violência e à transformação da horda paterna em uma comunidade de irmãos (Freud, 1921/1980e, p. 155).

Na leitura freudiana do mito da horda primeva, o mandamento "não matarás o totem" (Freud, 1913/1980b, p. 23) instaura a possibilidade de vivência em comunidade, e a lei do incesto aponta a interdição necessária para o reconhecimento do outro, favorecendo o laço social. Contudo, gostaríamos de fazer uma ressalva, visto que pensamos que o ato violento por si só não constituiria a civilização. Embora imperasse a lei do mais forte, inexistindo o laço social, na horda primeva, o parricídio como resposta à tirania desse pai, ao deixar vazio esse lugar, desfaz um arranjo e exige um passo a mais. A identificação e o reconhecimento entre os irmãos possibilita o laço social fundante da cultura: "ninguém mais pode tudo; somente a partir das leis, agora fundamentais, é que os sujeitos podem se situar" (Teixeira, 2013, p. 85).

Retomamos, então, o ponto de partida: o parricídio como crime. Poderíamos pensar que o crime é um ato que se inscreve nas origens da civilização, mas Freud nos convida a pensar o mito do Édipo como 
uma expressão do desejo humano que se coloca na constituição do sujeito não como uma escolha da ordem do singular. Cottet, em entrevista para Almeida (2008), revela:

Para Freud, não é somente o crime literário: é o crime universal, mítico, mas real mesmo assim - o assassinato do pai é o fundamento da sociedade. Logo, isto quer dizer que para Freud a possibilidade do criminoso está presente em cada um de nós. É necessário, por conseguinte, a normatividade edipiana, de alguma maneira, que canalize ou que apague o criminoso em nós (Cottet citado por Almeida, 2008, p. 9).

Nesta entrevista, Cottet, a partir da perspectiva freudiana, enfatiza a presença do criminoso em nós, sendo que, nesta perspectiva, a cultura precisa conter o excesso pulsional e a energia agressiva que habita cada sujeito. Não obstante, a lei, em seu sentido universal, fundada com a interdição do incesto e do parricídio, marca a passagem da natureza para a cultura, tornando-se imprescindível para a manutenção do laço social que já impõe renúncias ao sujeito. A constituição da civilização atravessa a compreensão da constituição do sujeito, já que a entrada na cultura pressupõe a abnegação ao apontar restrições que incidem de forma particular na sexualidade e na agressividade de cada sujeito e, dessa maneira, possibilita o laço social.

A concepção antropológica freudiana é trágica. Freud revela que "os homens não são criaturas gentis que desejam ser amadas e que, no máximo, podem defender-se quando atacadas; pelo contrário, são criaturas entre cujos dotes instintivos deve-se levar em conta uma poderosa quota de agressividade (Freud, 1930/1980f, p. 133).

A civilização precisa lançar mão de um gigantesco esforço para estabelecer os limites para a agressividade, que, para Freud (1930/1980f), se inscreve no processo de constituição subjetiva, na construção do eu diferente do outro. Sua origem pulsional se faz presente nas relações imaginárias, tendo seu fundamento na identificação narcísica no processo de constituição do eu.

Em A pulsão e seus destinos (1915/1980c), Freud ressalta o ódio como versão originária da hostilidade, que provém do repúdio primordial do eu narcisista em relação ao mundo exterior, ou seja, como uma reação de desprazer evocada pelos objetos do mundo exterior ao eu. Assim, o ódio apresenta uma proximidade com as pulsões de autoconservação na base do princípio de prazer.

Posteriormente, em O mal-estar na civilização, Freud (1930/1980f) situa a agressividade como constitutiva do eu e, na sua relação com 
os objetos, discute "que poderoso obstáculo à civilização a agressividade deve ser, se a defesa contra ela pode causar tanta infelicidade quanto a própria agressividade" (p. 168), já que esta se faz presente no fundamento do laço social, cabendo à sociedade propiciar a renúncia a essa pulsão. Todavia, como a agressividade está na ordem humana, ordem libidinal, quando dirigida a outrem deve ser introjetada, e neste processo ocorrerá uma transformação da agressividade em sentimento de culpa.

A percepção da alteridade se reinscreve trazendo o sentimento de culpa por ter desejado agredir o outro, que no enlaçamento social suporta consigo o desamparo. A verdade do desamparo possibilita a percepção da dependência entre os sujeitos. Assim, uma forma de conter o criminoso que nos habita seria a percepção da verdade do desamparo e a urgência do outro na nossa vida. Todavia, esta posição ética pode conter o criminoso em nós, mas não apagá-lo. A possibilidade do crime se mantém. Dessa forma, a leitura freudiana aponta para o crime como constitutivo, ainda que não tenha analisado nenhum crime factual.

Voltando a Freud, podemos dizer que, para ele, na origem da civilização temos dois crimes míticos: o parricídio, do qual temos o sentimento de culpa como consequência, e o incesto, como interdito universal que sustenta o campo da falta e institui a lei. Podemos afirmar que, para a psicanálise, a relação do sujeito com o pai primevo, mitificado após sua morte, institui, via sentimento de culpa, a alteridade em torno da qual se faz o laço social. Dessa forma, o sentimento de culpa pode ocupar um lugar estruturante.

Cabe ressaltar que o pensamento freudiano nos apresenta ao longo de seus textos algumas concepções sobre o sentimento de culpa, mas vamos nos ater neste artigo àquela que nos faz refletir sobre o laço social e tem importância na construção de conceitos como complexo de Édipo e supereu, os quais nos auxiliam na reflexão sobre a constituição do social e do sujeito. Como lembram Tendlarz e Garcia (2013), essas questões são importantes para fazermos uma diferenciação entre a culpa estrutural e a responsabilidade. Considerar a culpa como estrutural nos leva a entendê-la como uma causa para o ato ilícito e que a responsabilidade pelo ato é ao mesmo tempo um efeito e uma resposta do sujeito à culpa. Essa é a razão de Lacan, em 1932 (1987), estar preocupado com a diagnóstica da criminologia, pois esta permite traçar as relações e respostas que um sujeito pode estabelecer com essa culpa estrutural que faz com que o sujeito, nas palavras de Jacques-Alain Miller, seja sempre um "acusado" (2008).

Em Totem e tabu, Freud (1913/1980b), por meio da descrição do mito que explica a passagem da horda para a cultura, relaciona o sentimento de culpa às duas leis que fundam a cultura: o parricídio e o incesto. O sentimento de culpa que tem origem pós-assassinato do 
pai primevo é responsável por fundar o laço social. Esse sentimento de culpa tem como consequência a ambivalência afetiva pelo pai outrora mitificado.

Neste ponto, o pensamento freudiano opera uma aproximação entre o mito totêmico e o mito do Édipo e lança a ideia de que toda criança é um pequeno Édipo. Segundo Moreira (2004), o complexo de Édipo tem uma dupla função na vida do sujeito: inseri-lo como sexuado a partir das identificações e permitir sua entrada na cultura. O conceito de Complexo de Édipo é trabalhado na obra de Freud (1900/1980a) como um ponto de referência a partir do qual se organiza o desejo e, nesse sentido, cabe destacar o papel desempenhado pelas figuras parentais na vida psíquica das crianças.

Apaixonar-se por um dos pais e odiar o outro figuram entre os componentes essenciais do acervo de impulsos psíquicos que se formam nessa época [...]. Essa descoberta é confirmada por uma lenda da Antiguidade clássica [...] Rei Édipo e a tragédia de Sófocles que traz o seu nome (Freud, 1900/1980, p. 256).

A trama edípica marca o enfrentamento da criança das duas leis fundantes da organização social, inserindo-a como sexuado a partir das identificações e permitindo sua entrada na cultura. No que se refere ao sentimento de culpa percebemos que, do ponto de vista da cultura, sua relação com a alteridade funda o laço social e, do ponto de vista do sujeito, na cena edípica introduz a questão do outro a partir da constituição do supereu em que se dá o processo identificatório com a lei (Moreira, 2004).

Apesar de já realizar uma relação entre culpa e lei desde Totem e tabu, é no texto Criminosos em consequência de um sentimento de culpa, que Freud (1916/1980d) trará a discussão sobre os sujeitos que cometem crimes em nome de um obscuro sentimento de culpa. Rompendo com o pensamento da época de que a culpa poderia se instaurar somente após o sujeito cometer o crime, o autor dá à culpa o status de causa do crime. Ele percebe, a partir da sua clínica, que as condutas de transgressão da lei ocorriam porque eram proibidas e davam certo tratamento ao sentimento de culpa que atormentava o sujeito. Ao fazer o que era proibido o sujeito ia de encontro com a lei, com a punição que aliviava sua culpa. A ideia de que existem sujeitos que cometem atos criminosos para aliviar a culpa preexistente é uma das contribuições de Freud ao campo da criminologia.

Se temos, por um lado, uma culpa estrutural que é causa dos atos contra a lei, por outro lado, esses atos não são os únicos meios de se responder à culpa. Como lembram Tendlarz e Garcia (2013), uma das formas de lidar com essa culpa é o sintoma. No entanto, mesmo quando não temos respostas pelos sintomas e sim pelos atos, é importante destacar a posição do sujeito em relação ao ato em 
função da estrutura, o que muda o encaminhamento da direção do caso. Mais uma vez nos apoiamos em Tendlarz e Garcia (2013) quando dizem que

as diferentes estruturas clínicas seguem caminhos diversos no tocante ao processamento da culpa: na neurose temos a vacilação em atribuí-la ao eu ou ao Outro; na melancolia, a certeza psicótica de sua própria culpa; na paranoia, a certeza psicótica da culpa do Outro; e na perversão, a negação da culpa (Tendlarz, \& Garcia, 2013, p. 41).

A possível vinculação entre culpa e crime anunciada no texto freudiano é inovadora. No entanto, a teoria lacaniana avança ainda mais nas reflexões que articulam criminologia e psicanálise.

\section{Psicanálise e criminologia: crimes do isso, crimes do eu}

Se Freud fala do criminoso potencial, Lacan aborda respostas possíveis ao sentimento de culpa estrutural do sujeito. Assim, se nosso objetivo é abordar os atos infracionais a partir da psicanálise, devemos atentar para duas questões caras a Lacan em seus textos sobre criminologia entre os anos 1930 e 1950. Enfatizam-se duas: a questão da responsabilidade, principalmente em relação à delinquência juvenil e suas penas; e a função criminogênica da sociedade, principalmente em relação à dialética entre lei e crime. Essas questões são abordadas pelo autor desde a tese de 1932 sobre a psicose paranoica até os textos sobre agressividade, função em criminologia e premissas à criminologia. Mas o que salta aos nossos olhos é que estas são respostas do sujeito que não passam pela dimensão dos sintomas, e sim dos atos. Cremos que os atos infracionais também não passam pela estrutura clássica do sintoma e, por isso, a questão dos atos pode ser elucidativa para abordar os atos infracionais. Lacan aborda esse tema a partir da noção freudiana de supereu e discute a questão da periculosidade e das penas desses sujeitos.

Nesses textos sobre criminologia, Lacan parte do aporte freudiano de 1916, que, por sua vez, é um texto preparatório sobre a questão do supereu que virá à luz em 1923. Lacan baseia-se principalmente em uma ressalva feita por Freud: se as pessoas cometem crimes por meio de uma culpa inconsciente, há um grupo de pessoas que também cometem ou cometeram crimes, mas com quem o problema do tratamento da culpa toma outra dimensão devido à resposta do sujeito ao próprio ato. Diz Freud: "Entre criminosos adultos devemos, sem dúvida, excetuar aqueles que cometem crimes sem qualquer sentimento de culpa; que não desenvolveram quaisquer inibições 
morais ou, em seu conflito com a sociedade, consideram sua ação justificada" (Freud, 1916/1980d, p. 348).

Essas exceções, curiosamente, tornaram-se um importante programa de pesquisa tanto para Paul Guiraud como para Lacan. Será com base nesse programa que ambos falarão em crimes do eu e crimes do isso. Essa distinção é proveniente de dois artigos de Guiraud em que ele pretende analisar os crimes a que chama de "assassinatos imotivados": crimes que seriam cometidos sem motivo aparente, de maneira impulsiva, geralmente extremamente violentos contra desconhecidos e que provocam o que foi pelo autor nomeado como fabulação novelesca depois do crime. A explicação dada por Guiraud (1931/1994) é de que se trata de atos feitos por um sujeito para se livrar do kakon: o mal que acossa o sujeito. Se tomarmos as elaborações mais tardias de Lacan (1946/1998a) sobre a passagem ao ato, veremos que esse kakon é nada mais do que o objeto a presente sem mediações simbólicas que façam uma separação entre o sujeito e o objeto. Ou, como diz Serge Cottet, a passagem ao ato criminoso seria "uma separação selvagem do objeto de gozo que põe fim à angústia" (Cottet, 2009, s.p.). Daí esses crimes imotivados terem em comum um aspecto de libertação do mal que acossa o sujeito, o gozo invasor que é respondido no nível da agressão especular no registro do imaginário.

Lacan introduz sua tese a partir, de um lado, dessa questão mais geral destacada por Guiraud, e, de outro lado, a partir de uma questão mais específica: a questão do diagnóstico. A tese de 1932 (Lacan, 1932/1987) pretende estabelecer uma diferenciação diagnóstica dentro do campo da paranoia: trata-se da paranoia de autopunição, distinta das paranoias reivindicatórias. De acordo Lacan (1950/1998c), essas questões em criminologia são importantes para pensarmos as periculosidades dos sujeitos, ou seja, para teoria lacaniana somente pela clínica se poderá chegar a essa definição, desde que se leve em conta, apesar das diferenças clínicas, o caso a caso da experiência. Lacan (1946/1998a) afirma, ainda, que os paranoicos querelantes seriam mais perigosos do que as psicoses autopunitivas, e as duas, por sua vez, seriam mais perigosas que os delirantes interpretativos. O autor aborda essa questão a partir da distinção de Guiraud (1931/1994) entre crimes do eu e crimes do isso e introduz a ideia dos chamados crimes do supereu.

Guiraud (1931/1994) realiza, como visto, uma distinção entre crimes do eu (ou dos interesses) e crimes do isso (que seriam os crimes pulsionais), e Cottet (2008) redefine esses dois tipos de crime, a partir da teoria milleriana, como crimes da utilidade e crimes do gozo. Já Tendlarz e Garcia complementam a reflexão com a ideia de que nos crimes do eu o indivíduo se comporta segundo sua vontade, com a ilusão de plena liberdade (2013, p. 72) e os crimes do isso seriam próprios à esquizofrenia em que o eu seria um espectador passivo e 
surpreendido. Para Cottet (2008), os crimes do eu teriam elementos da identificação simbólica: ideais de justiça, de toda potência, um idealista passional reivindicador.

Lacan, por sua vez, determina outra classificação: os crimes dos querelantes e os crimes dos delírios de autopunição se situariam nos crimes do supereu. Enquanto os assassinatos imotivados se situariam nos crimes do isso em que o sujeito pretende não agredir seu eu, mas matar o mal que há nele, no caso das psicoses de autopunição, Lacan debruça-se no fator retificador que o crime e o castigo podem ter para esses sujeitos, colocando em cena o que funda a cultura: a dialética entre a lei e o crime que se realiza no castigo. Vale notar que estamos falando aqui em castigo, e não em prisão, o que já traz a dialética que funda a cultura.

Cottet, em entrevista para Almeida (2008), revela que "existem crimes paranóicos que têm exatamente esta estrutura, a saber, o sujeito não sabe que, golpeando um rival, ele golpeia o seu ideal" (Cottet citado por Almeida, 2008, s.p.). Este recorte nos interessa por acreditarmos que esta lógica pode oferecer algum elemento que auxilie a compreensão da razão pela qual se deu, em 2011, um aumento nos homicídios de jovens brasileiros com idades entre 15 e 24 anos em relação ao ano de 2010. O prefácio do Mapa da Violência de Waiselfisz (2013) revela que:

Como mostra o diagnóstico, os homicídios são hoje a principal causa de morte de jovens de 15 a 24 anos no Brasil e atingem especialmente jovens negros do sexo masculino, moradores das periferias e áreas metropolitanas dos centros urbanos. Dados do SIM/DATASUS do Ministério da Saúde mostram que mais da metade dos 52.198 mortos por homicídios em 2011 no Brasil eram jovens ( 27.471 , equivalente a $52,63 \%$ ), dos quais $71,44 \%$ negros (pretos e pardos) e $93,03 \%$ do sexo masculino (Waiselfisz, 2013, p. 8).

Os dados do Mapa da Violência (Waiselfisz, 2013) são construídos a partir do estudo dos atestados de óbito que devem determinar a causa da morte seguindo os princípios do CID 10, sendo que este manual estabelece, no Capítulo XX, morte por causas externas. O documento apresenta três tipos de causas externas: acidente de transporte, homicídios e suicídios. Waiselfisz reconhece a limitação do instrumento de pesquisa, mas revela que, "apesar dessas limitações do sistema, existe amplo consenso em indicar, por um lado, a sua enorme importância e, por outro, a necessidade de seu aprimoramento" (Waiselfisz, 2013, p. 17).

A mortalidade por homicídio é interpretada "como indicador por excelência de formas conflitivas de relacionamento interpessoal que acabam com a morte de algum dos antagonistas" (Waiselfisz, 2013, p. 
16). Assim, perguntamos: quem seria o maior ator do conflito interpessoal com nossos jovens pobres e negros? A resposta é complexa porque o ator do conflito pode não ter rosto e representar as formas de segregação e exclusão da nossa sociedade. Mas quem puxa o gatilho da arma? Muitos podem ser os sujeitos armados que descarregam seus ódios, suas moralidades, suas fantasias de justiceiros, mas um dos possíveis agentes dos homicídios pode ser encontrado em outros jovens negros e pobres que estabelecem guerras por territórios. É neste ponto que a lógica dos crimes do eu nos interessa, porque, conforme apontamos antes, "o sujeito não sabe que, golpeando um rival, ele golpeia o seu ideal" (Cottet citado por Almeida, 2008, s.p.).

De acordo com Machado (2013), na teoria lacaniana encontramos uma reflexão sobre os crimes do eu, que podem ser compreendidos como os crimes que têm um objetivo exterior ao próprio crime, ou seja, "mata-se para roubar, por vingança, para usurpar o poder; por sentir-se perseguido, humilhado, ou para se livrar de vozes atormentadoras. Mata-se para derrubar um regime político, para dominar uma nação, para defender uma crença" (Machado, 2013, s.p.). Podemos pensar que esse tipo de crime se localiza em um circuito imaginário, enquanto os crimes de autopunição, ou crimes do supereu, estariam em um circuito do simbólico (Machado, 2014). Para a autora, os crimes do eu têm uma ordenação simbólica, ou seja, um motivo, e por isso foram denominados por Miller (2008) como crimes de utilidade, visto que apresentam uma causa que lhes é exterior.

Por sua vez, Lacan (1932/1987) nos apresenta os crimes do isso, que segundo Cottet (citado por Almeida, 2008, s.p.) "são os crimes cuja brutalidade e impulsividade assinalam a esquizofrenia, como os crimes imotivados de Guiraud (1994)". Pensamos que são poucos os crimes do isso no universo na criminalidade juvenil, mas, quando aparecem, possuem um forte apelo de mídia, em imagens que associam os jovens negros e pobres a seres cruéis e indignos da "boa vontade" social.

Um exemplo de caso de crime do isso, imotivado, é o que é apresentado sob o nome de "Pense nessa criança" (Calazans, Resende, \& Azevedo, 2014). Trata-se do caso de um adolescente que comete um matricídio. Ele o faz em função da dificuldade em tratar da angústia pelo caminho do simbólico e do sintoma. Quando defrontado com a repetição de uma situação em que seria colocado em um lugar de "funcionário" da mãe, começa com ela uma discussão. Nessa discussão, pega uma faca e escuta da mãe, grávida: "pense nessa criança". Diante dessa fala o jovem diz não lembrar mais de nada; esfaqueou a mãe e não consegue localizar o motivo. Em passagem em que discute o crime do isso, Lacan problematiza essa "imotivação", fazendo com que se reflita sobre a ideia de que o 
que está em jogo aqui é menos um 'imotivado' e mais uma localização precisa do sujeito com os recursos que tem para lidar com a angústia: "Em um momento, o futuro se lhe afigurou fechado" (Lacan, 1932/1987, p.298). Esse futuro fechado é próprio da passagem ao ato.

Miller adota uma nomenclatura diferente para os crimes do isso. Para ele, trata-se de crimes do gozo. Nas palavras de Machado:

Como paradigma, foi adotado o crime do isso, que Miller renomeia como crime de gozo. Para esse autor, existem os crimes de utilidade, que de certa forma recobrem os crimes do eu e os de punição, nos quais a causa está fora dele, seja roubo, castigo ou vingança. Existem também os crimes de gozo, nos quais o objetivo é o próprio crime. É por romper com a lógica da utilidade que o crime de gozo choca e faz crer que não há nenhuma causa implicada (Machado, 2014, p. 5).

Podemos ver essas diferenciações entre crimes de utilidade e crime do gozo a partir de alguns exemplos de atos infracionais cometidos por adolescentes. O caso de Pedro, por exemplo, apresentado no texto "Qual o tempo de uma medida?" (Silva, Porto, Ferrari, Cavalieri, $\&$ Andrade, 2014), ilustra bem o que podemos chamar de crimes do eu ou de utilidade. Pedro é um adolescente envolvido com a criminalidade desde os 12 anos de idade. Inicialmente, de acordo com ele, “apenas traficava de leve. Após a morte de um amigo, passou a traficar para comprar arma de fogo e se proteger, se envolvendo assim de cabeça com a criminalidade" (Silva et al., 2014, p. 79).

Nesta passagem podemos notar que a entrada no crime se dá por uma utilidade: seja para adquirir bens de consumo, o que o levou a traficar "de leve"; seja para a própria proteção, que o levou a se envolver "de cabeça" para comprar armas de fogo após o evento traumático da morte de um amigo. Segundo a equipe da unidade de semiliberdade que o acompanhou, Pedro era imediatista, "que não conta até dez", que age por impulsos e não dá conta de seguir as regras da unidade. Esse curto-circuito, que podemos nomear como passagem ao ato, é somente posto em questão no espaço de escuta oferecido pela equipe, o que o leva a investir em outras ações para além da criminalidade. Como diz o adolescente: "eu não quero passar a minha vida de menor preso". Com essa vacilação da certeza, outros investimentos se tornaram possíveis, como um namoro e um planejamento para o futuro que não passe pela criminalidade. Segundo a equipe, ficou entendido que, se, por um lado, ele cumpre precariamente alguns eixos da medida (como escola e profissionalização), por outro lado, ele se posiciona diante de sua relação com o Outro de uma maneira que não passa mais pela 
criminalidade. Essa mudança pode ser notada na fala do próprio adolescente, que afirma que, quando evade da medida, ele retorna à unidade porque "quero eliminar os meus problemas, resolver da melhor forma" (Silva et al., 2014 p. 79).

Já os crimes de gozo, em que essa causa exterior não existe e o objetivo do crime se funde com o próprio crime estão, segundo Machado (2014), na contramão da utilidade, já que há nesses atos violentos uma abertura ao gozo em uma perspectiva tão singular que não se tem alcance da causa que o motiva. Sem a função de utilidade, a causa não consegue ser transmitida no ato, tampouco pode ser compartilhado seu entendimento. São esses pontos que levam a autora a apostar que haveria aí a concorrência da pulsão no seu aspecto necessário, acéfalo e irruptivo. Em outras palavras, são crimes que se orientam pelo objeto em uma busca de satisfazer ao gozo em sua particularidade. Como o gozo está na lógica do excesso, e se impõe ao sujeito como necessário, como uma exigência que nada tem a ver com o bem-estar, a satisfação é alcançada a qualquer preço.

Isso é o que encontramos no caso da adolescente L. intitulado "A família na medida" (França \& Santos, 2015). Trata-se de uma adolescente de 15 anos que desde os 11 anos se encontra envolvida com a criminalidade (dano ao patrimônio, ameaças, tráfico e assaltos a mão armada) e que diz no início da medida não ter motivo para a prática de tais atos, embora tente localizar no abandono familiar a causa de seus atos. Dois aspectos se destacam nas falas e atuações da adolescente no cumprimento da medida: de um lado, a queixa de que há um gozo ilimitado e que poucos conseguem por limites (o pai, primeiramente e depois o irmão, ambos envolvidos também com a criminalidade); de outro lado, uma errância que a leva a evadir-se diversas vezes da medida a convite de outras adolescentes para traficar e que a leva a um curto-circuito drogas-prostituição-drogas. Tanto o ilimitado do gozo que a invade quanto o gozo da presença de um objeto que se autorreferencia nos permitem entrever aí um aspecto dos crimes do gozo, em que a utilidade é quase nunca apontada e, quando faz questão, é sempre de maneira precária: "roubo pra comer as coisas, roubo porque isso é viciante" (França \& Santos, 2015, p. 101). Durante a medida houve a oferta de um encaminhamento para a escuta em outra instituição da rede; porém, segundo a própria equipe, não houve implicação da adolescente ao tratamento. Nesse aspecto, esse curto-circuito de gozo não se rompeu, ficando a adolescente presa a um curto-circuito que a leva a continuar na criminalidade sem deslocar da família a causa desse envolvimento, impedindo uma subjetivação de seus atos. 


\section{Considerações finais}

Com esses exemplos foi possível notar que as reflexões psicanalíticas sobre o crime podem oferecer alguns subsídios para compreender 0 campo que articula adolescência e criminalidade. A violência urbana hoje parece se presentificar nos diversos atos em que a satisfação pulsional não encontra mediação simbólica. Contudo, podemos apontar alguns recursos que, ao se antepor ao real, fazem a medição entre o real e o sujeito servindo de bússola que os orienta frente ao mal-estar na civilização tão presente na sociedade atual.

Nossa reflexão pode contribuir para que se vislumbrem direções possíveis de intervenção junto aos adolescentes autores de ato infracional que cumprem medida, porque se faz necessário considerar que a consciência do ato infracional não cobre a perspectiva da assunção subjetiva pelo seu ato. E que o ato responde a diferentes questões sociais, grupais, econômicas, mas também da dinâmica psíquica. Assim, é fundamental escutar o adolescente para compreender o lugar do ato infracional na sua economia psíquica, pois o ato pode se aproximar a um crime do isso, ou a um crime de utilidade, ou ainda a um crime edípico.

Dessa forma, a partir do presente trabalho podemos refletir sobre possibilidades de intervenção no contexto do cumprimento de uma medida socioeducativa ao contribuir com o fazer de cada caso, acompanhado na proposta coletiva das políticas públicas. Isso não significa universalizar e ou protocolizar as intervenções, nem tampouco constituir manuais de orientação, mas tomar o particular como orientação para a política e os seus direcionamentos no campo jurídico e psicossocial.

\section{Referências}

Almeida, P. (2008). Criminalidade e psicanálise: entrevista com Serge Cottet. Estudos de psicanálise, (31), 09-16. Recuperado em 01 de novembro de 2015, de http: //pepsic. bvsalud.org/scielo. php?script=sci_arttext\&pid=S0 $100-34372008000100002 \&$ lng $=$ pt\&tlng $=p t$

Aquino, L. G. (2012). Crianças e Adolescentes: o ato infracional e as medidas socioeducativas. Âmbito Jurídico, 15(99). Recuperado em 01 de novembro de 2015, de http://www.ambitojuridico.com.br/site/?n_link=revista_artigos_leitura\&artigo_id= 11414

Calazans, R., Resende, M. S., \& Azevedo, E. C. (2014). Pense nessa Criança. In J. O. Moreira, A. M. C. Guerra, J. M. P. Souza (Org.), Diálogos com 0 campo das medidas socioeducativas: 
conversando sobre a semiliberdade e a internação (pp. 153168). Curitiba: Editora CRV.

Cottet, S. (2009). Criminologia lacaniana. Revista Eletrônica do Núcleo Sephora, IV(8), 107-123. Recuperado em 30 de outubro de 2015, de http://www.isepol.com/asephallus/numero_08/revista_8.pdf

França, F. A., \& Santos, N. A. P. (2015). A Família na Medida: ( Im)possibilidades de um laço familiar a adolescente e seus familiares. In J. O. Moreira, J. Marcondes, P. M. Rocha (Org.), Diálogos com o campo das medidas socioeducativas: conversando sobre a acolhida, os eixos e o desligamento (pp. 97-101). Curitiba: CRV.

Freud, S. (1980a). A interpretação de sonhos. In S. Freud, Edição Standard Brasileira das Obras Psicológicas de Sigmund Freud (J. Salomão, trad., Vol. IV, pp. 1-330). Rio de Janeiro: Imago. (Trabalho original publicado em 1900).

Freud, S. (1980b). Totem e tabu. In S. Freud, Edição Standard brasileira das obras psicológicas completas de Sigmund Freud (J. Salomão, trad., Vol. XIII, pp. 17-192). Rio de Janeiro: Imago. (Trabalho original publicado em 1913).

Freud, S. (1980c). A pulsão e seus destinos. In S. Freud, Edição Standard Brasileira das Obras Psicológicas de Sigmund Freud (J. Salomão, trad., Vol. XIV, pp. 59-124). Rio de Janeiro: Imago. (Trabalho original publicado em 1915).

Freud, S. (1980d). Criminosos em consequência de um sentimento de culpa. In S. Freud, Edição Standard brasileira das obras psicológicas completas de Sigmund Freud (J. Salomão, trad., Vol. XIV, pp. 325-350). Rio de Janeiro: Imago. (Trabalho original publicado em 1916).

Freud, S. (1980e). Psicologia de grupo e análise do ego. In S. Freud, Edição Standard Brasileira das Obras Psicológicas de Sigmund Freud (J. Salomão, trad., Vol. XVIII, pp. 89-182). Rio de Janeiro: I mago. (Trabalho original publicado em 1921).

Freud, S. (1980f). O mal-estar na civilização. In S. Freud, Edição Standard brasileira das obras psicológicas completas de Sigmund Freud (J. Salomão, trad., Vol. XXI, pp. 81-171). Rio de Janeiro: Imago. (Trabalho original publicado em 1930).

Guiraud, P. (1994). Os assassinatos imotivados. Revista Opção Lacaniana, (9), 87-91. (Trabalho original publicado em 1931).

Lacadée, P. (2007, 16 de junho). O risco do adolescente. Estado de Minas, Caderno Pensar 3.

Lacan, J. (1987). Da psicose paranóica e suas relações com a personalidade. (A. Menezes, M. A. C. Jorge e P. M. Silveira J r., trad.). Rio de Janeiro: Forense Universitária. (Trabalho original publicado em 1932). 
Lacan, J. (1998a). Formulações sobre a causalidade psíquica. In J. Lacan, Escritos (pp. 152-194). Rio de Janeiro: Jorge Zahar Editor. (Trabalho original publicado em 1946).

Lacan, J. (1998b) A agressividade em psicanálise. In J. Lacan, Escritos (pp. 104-126). Rio de Janeiro: Jorge Zahar Editor, (Trabalho original publicado em 1948).

Lacan, J. (1998c). Introdução teórica às funções da psicanálise em criminologia. In J. Lacan, Escritos (pp. 127-151). Rio de Janeiro: Jorge Zahar Editor. (Trabalho original publicado em 1950).

Lei Federal no 7.209, de 11 de julho de 1984. (1984, 11 de julho). Altera dispositivos do Decreto-Lei no 2.848, de 07 de dezembro de 1940 - Código Penal, e dá outras providências. Brasília, DF: Presidência da República: Casa Civil. Recuperado em 30 de outubro de 2015, de http://www. planalto.gov.br/ccivil_03/decretolei/del2848compilado.htm

Lei Federal no 8.069, de 13 de julho de 1990. (1990, 13 de julho). Dispõe sobre o Estatuto da Criança e do Adolescente (ECA). Brasília, DF: Presidência da República: Casa Civil. Recuperado em 02 de outubro de 2014, de http://www. planalto.gov.br/ccivil/LEIS/L8069.htm

Machado. O. (2013). A violência e a nova ordem. In Conversações ENAPOL 2013. Relatório de Grupo de Trabalho da Escola Brasileira de Psicanálise. Recuperado em 20 de agosto de 2015, de http://www.enapol.com/pt/template. php?file=LasConversaciones-del-ENAPOL/La-violencia-y-el-nuevoorden/Ondina-Machado.html

Machado. O. (2014). Violar Corpos. Opção Lacaniana nova série, ano 5(13), 1-8. Recuperado em 30 de outubro de 2015, de http://www.opcaolacaniana.com.br/pdf/numero_13/Violar_corp os.pdf

Miller, J. A. (2008). Nada é mais Humano que o crime. Recuperado em 30 de outubro de 2015, de http://www. institutopsicanalisemg.com. br/psicanalise/almanaque/04/textos/Nada\% 20\% 20mai s\% 20humano\%20que\% 200\% 20crime.pdf

Moreira, J. O., Romagnoli, R. C., Melgaço, P., Dias, A. F. G. \& Bouzada, G. C. F. A medida socioeducativa de internação sob uma lente foucaultiana. Revista Polis e Psique, 4(1), 73-89. Recuperado em 26 de setembro de 2015, de http://seer.ufrgs.br/index. php/PolisePsique/article/view/46017

Moreira, J. O. (2004). Édipo em Freud: o movimento de uma teoria. Psicologia em Estudo, 9(2), 219-227. Recuperado em 08 de agosto de 2015, de http://dx.doi.org/10.1590/S141373722004000200008 
Saraiva, J. B. C. (2009). Adolescente em conflito com a lei: da indiferença à proteção integral: uma abordagem sobre responsabilidade civil. Porto Alegre: Livraria dos Advogados.

Silva, T. L., Porto, C. M., Ferrari, A. T. R., Cavaliere, I. C., \& Andrade, E. S. (2014). Qual o tempo de uma medida? In J. O. Moreira, A. M. C. S. Guerra, \& J. Marcondes (Org.), Diálogos com o campo das medidas socioeducativas: conversando com a semiliberdade e a internação, (pp. 79-84). Curitiba: CRV.

Teixeira, L. C. (2013). A culpa na constituição do sujeito e do social. In A. B. Rosário, \& J. M. Oliveira, Culpa e laço social: possibilidades e limites (Vol. 1, pp. 83-94). Barbacena: EdUEMG.

Tendlarz, S. E., \& Garcia, C. D. (2013). A quem o assassino mata? O serial killer à luz da criminologia e da psicanálise. São Paulo: Editora Atheneu.

Waiselfisz, J. J. Mapa da Violência: homicídios e juventude no Brasil. Brasília: Secretaria-Geral da Presidência da República; Secretaria Nacional de Juventude. Recuperado em 26 de setembro de 2015, de http://www.mapadaviolencia.org.br/pdf2013/mapa2013_homici dios_juventude.pdf

\author{
Endereço para correspondência \\ Juliana Marcondes Pedrosa de Souza \\ Universidade Federal de São J oão del Rei - UFSJ \\ Programa de Pós-graduação em Psicologia \\ Praça Dom Helvécio, 74, Campos Dom Bosco, CEP 36301-160, São João del Rei - \\ MG, Brasil \\ Endereço eletrônico: juliana.marcondes@yahoo.com.br \\ Roberto Calazans \\ Universidade Federal de São J oão del Rei - UFS J \\ Programa de Pós-graduação em Psicologia \\ Praça Dom Helvécio, 74, Campos Dom Bosco, CEP 36301-160, São João del Rei - \\ MG, Brasil \\ Endereço eletrônico: roberto.calazans@gmail.com \\ J acqueline de Oliveira Moreira \\ Pontifícia Universidade Católica de Minas Gerais - PUC-Minas \\ Programa de Pós-graduação em Psicologia \\ Av. I taú, 525, Bairro Dom Cabral, CEP 30535-012, Belo Horizonte - MG, Brasil \\ Endereço eletrônico: jackdrawin@yahoo.com.br
}

Recebido em: 30/06/2016

Reformulado em: 17/11/2016

Aceito em: $17 / 11 / 2016$ 
Juliana Marcondes Pedrosa de Souza, Roberto Calazans,

J acqueline de Oliveira Moreira

\section{Notas}

* Pós-Doutoranda pela Universidade Federal de São João del Rei; Belo Horizonte; Brasil; Doutora em Psicologia pela Pontifícia Universidade Católica de Minas Gerais. ** Professor do Programa de Pós-Graduação em Psicologia pela Universidade Federal de São João del Rei; São João del Rei; Brasil; Doutor em Teoria Psicanalítica pela Universidade Federal do Rio de Janeiro.

*** Professora Adjunta III da Pontifícia Universidade Católica de Minas Gerais; Professora do Programa de Pós-Graduação da Pontifícia Universidade Católica de Minas Gerais, Belo Horizonte; Brasil; Doutora em Psicologia Clínica pela Pontifícia Universidade Católica de São Paulo; Bolsista PQ2 CNPQ. Pesquisadora PPM FAPEMIG ano 2013 - 2016. 